\title{
Blade Runner BR, 2071
}

sitiando fronteiras entre Ceilândia e

http://dx.doi.org/10.11606/ Brasília (o cinema de Adirley Queirós)

\section{Marco Antonio Gonçalves}

Universidade Federal do Rio de Janeiro/ Rio de Janeiro, R], Brasil

Este artigo analisa o cinema de Adirley Queirós tomando seu primeiro longa metragem, A cidade é uma só? (2013), como fio condutor da interpretação. Seu cinema, situado entre Brasília e Ceilândia, sitia lugares e espaços naturalizados, dessubstancializa conceitos como os de localidade, periferia, identidade, memória, finitude, história, arquitetura, ficção, documentário. Seu cinema evoca diálogos fecundos através de figurações da alteridade, da distopia, da entropia em cenários urbanos posmetropolis, em que se percebe a insurgência das cidades satélites enquanto lócus de contestação e crítica a projetos, tão redentores quanto autoritários, como os propostos pela ideologia modernista que planeja e institui Brasília, nos anos 1950 e 1960, no Brasil central.
ABSTRACT This article analyzes the cinema of Adirley Queirós taking his first feature film 'Is the City Only One'? (2013) as a starting point. His cinema, located halfway between Brasilia and Ceilândia, contests naturalized places and spaces, de-substantializing concepts such as those of locality, periphery, identity, memory, history, architecture, fiction, and documentary. His cinema produces fruitful dialogues through the use of figures of alterity, dystopia, and entropy in post-metropolitan urban scenarios, where the insurgency of satellite cities becomes a locus of contestation and criticism of mega-projects, as redemptive as they are authoritarian, such as the modernist ideology materialized in the planning and building of the capital Brasília, in the 1950s and 1960s, in central Brazil.
Antropologia Visual, Cinema, Documentário, Brasília, Ceilândia, Memória.

KEYWORDS

Visual Anthropology, Cinema, Documentary, Brasília, Ceilândia, Memory 


\section{A CIDADE É UMA Só?}

Este artigo analisa o cinema de Adirley Queirós tomando seu primeiro longa-metragem, A cidade é uma só? (2013), como fio condutor da interpretação. Seu cinema, situado entre Brasília e Ceilândia, sitia lugares e espaços naturalizados, dessubstancializa conceitos como os de localidade, periferia, identidade, memória, finitude, história, ficção, documentário. Seu cinema evoca diálogos fecundos através de figurações da alteridade, da distopia, da entropia em cenários urbanos posmetropolis, em que se percebe a insurgência das cidades satélites enquanto lócus de contestação e crítica a projetos, tão redentores quanto autoritários, como os propostos pela ideologia modernista que planeja e institui Brasília, nos anos 1950 e 1960, no Brasil central. Brasília como miragem, holograma, ilusão, apreendida "da perspectiva da janela" dos ônibus nos grandes trajetos entre os "satélites" e o "planeta", surge multifacetada, contraditória: exibe seus conflitos territorializados, camadas superpostas de segregação espacial, social e racial.

A primeira parte do artigo, A cidade é uma só?, apresenta uma leitura do filme reconstituindo sua cena etnográfica. Adirley, "o Spike Lee" da Ceilândia examina as proposições gerais de seu cinema, seu lugar de locução, a "quebra de gramática", seu inconformismo. Sitiando fronteiras: ficção/documentário investe nos princípios que estruturam seu cinema, suas concepções de ficção, documentário, alteridade, cinema de combate, cinema visceral, em que o corpo, a "correria" e a subjetividade ocupam lugares centrais. Anarquitetura, sequestrando espaços explora o reviramento de sentido que seu cinema propõe sobre Brasília, jogando luz em sua "desurbanização urbanizante", seu "anarcoplanejamento", aprofundando novas percepções espaciais que fazem colidir o plano do cinema com o plano piloto de Brasília, expresso nas deambulações dos personagens do filme que contestam um determinado ordenamento urbano. Efeito Blade Runner: entropia, distopia pensa o cinema de Queirós como efeito, imagens que têm o poder de produzir novos modos de compreensão do mundo ao explorarem a potência da destruição, da raiva, da contradição, do inconciliável como mundos possíveis e futuros plausíveis. Ceilândia, que foi produzida em 1971 pela "Campanha de Erradicação das Invasões (CEI) + lândia” é, agora, literalmente invasora. Retorna à Brasília, como um bumerangue lançado há 50 anos, construindo novos espaços significacionais.

\section{A CIDADE É UMA SÓ?}

Análises antropológicas que tomam as imagens de filmes como material privilegiado, não necessariamente compreendem o filme como um espelho ou reflexo direto de uma sociedade ou de um mundo. Neste sentido, proponho aqui uma reconstituição narrativa-etnográfica-visual que permita o leitor acompanhar planos e sequências do filme que serão capitais para a compreensão da análise realizada. 
Iniciemos pelo começo. O plano piloto é desenhado como numa planta de arquitetura. O que entendemos por Brasília vai ganhando contorno e forma para em seguida ser incinerado. Nancy, Dildu, Zé Antônio, Marquim são os personagens pelos quais as teias complexas das relações entre Brasília e Ceilândia são tecidas.

Brasília é narrada, em voice over, pelos seus idealizadores, vozes que vem do rádio do Santana, personagem não menos importante do filme: "Deste Planalto Central, desta solidão que em breve se transformará em cérebro das altas decisões nacionais, lanço os olhos, mais uma vez, sobre o amanhã do meu país, e antevejo esta alvorada com uma fé inquebrantável, e uma consciência sem limites no seu grande destino". "Aí está Brasília, tantos anos passados, a cidade que JK construiu com tanto entusiasmo" (Oscar Niemeyer). As frases de JK e Oscar Niemeyer são ouvidas agora em um cenário de ruas tortuosas, sem planejamento, sem calçamento. Vemos Ceilândia evocar uma outra ordem urbana distante do plano piloto.

Nancy, antes de entrar na sua música-história-memória "A cidade é uma só", faz um prólogo com outra música, que apresenta de forma explicita o imaginário sobre o plano piloto: "Eu tinha plano de morar no plano, de estudar no plano, de trabaIhar no plano, de viver no plano, ah meu grande mano, que ledo engano, não deu mais para segurar... Que vida malvada, que vida arredia, passados os anos, tantas lutas, tantos planos jogaram meu plano na periferia."

Nancy retoma e subverte sua própria história quando canta, hoje, a música que cantou quando criança em 1970 no coral formado por colegas de sua escola na Vila do $|A P|^{2}$ que exaltava, através de um jingle, a remoção das chamadas invasões do Plano Piloto de Brasília para as cidades satélites, no caso Ceilândia.

Ceilândia surge, insistentemente no discurso de Nancy como palavra-valise, resultado da aglutinação de outras palavras produzindo o neologismo Ceilândia: Campanhade Erradicação das Invasõescomo prefixo de lândia. A ênfase no momento originário de sua criação desperta novas possibilidades de significação, potência que se transforma em ato, intervenção sobre o mundo, encerrando a proposta do filme que toma a música homônima como título acrescido do sinal de interrogação, desestabilizando o conceito de Brasília.

Uma reportagem de TV, dos anos 1970, justifica a erradicação das invasões: narra a história das migrações, dos trabalhadores recrutados em todo o Brasil, das invasões de áreas com pouca habitabilidade, "sem higiene e conforto" e nos diz que a solução encontrada pelos administradores foi realizar a mudança daquelas pessoas para onde se pudesse "harmonizar os serviços públicos e dar condições melhores de vida àquela gente até então favelada". Nancy rebate, dizendo: "eles queriam na verdade achar um lugar para jogar aquele monte de pobre. Tirar de próximo de Brasília a coisa feia e trazer para um lugar distante. Aqui era muito mato, muita poeira e nenhuma infraestrutura. Faziam um X no seu barraco... você foi sorteado para ir pra Ceilândia... não tinha opção de ficar, eles queriam o terreno, queriam o espaço".
1 | Discurso proferido por Juscelino Kubitscheck na ocasião do primeiro ato assinado na futura capital em 1956.

2 | Vila do IAPI e outras áreas como Morro do Urubu, Querosene, Curral das Éguas (pequenos aglomerados somando uns 15 mil barracos nas redondezas do Plano Piloto) foram alvos da Campanha de Erradicação das Invasões em Brasília que deu origem às cidades satélites (Severo, 2014: 34). Em 1970, 0 governador Hélio Prates da Silveira cria este projeto de erradicação das chamadas favelas de Brasília e em 1971 foram demarcados 17.619 lotes numa área de 20 quilômetros quadrados o que veio a se transformar a cidade satélite de Ceilândia. 
Nancy visita com Queirós o arquivo de Brasília buscando encontrar a materialização de sua história em imagens e sons. Não encontram nada sobre o jingle "A cidade é uma só". O filme toma o compromisso de realizar imageticamente o jingle. Com perdão da paráfrase, a história se repete: a primeira vez como tragédia, e agora 40 anos depois, como ficção. Meninas de uma Escola Pública de Ceilândia foram recrutadas pelo filme e, vestindo os uniformes da época, penteadas como nos anos 60, fazem a performance sob o comando e direção de Nancy. Ojingle torna-se indiciático quando Queirós associa uma das meninas do coro, pela semelhança física, à Nancy de 1970. Este "documento de época", o jingle em preto e branco, é o transbordamento da imaginação de Nancy para a tela. O coro das crianças canta "A cidade é uma só": "Você que tem um bom lugar pra morar; Nos dê a mão ajude a construir nosso lar; Para que possamos dizer juntos a cidade é uma só; Você, você, você; Você vai participar; Porque, porque, porque; A cidade é uma só; Vamos sair da invasão; A cidade é uma só".

A música-mantra do filme permite que Nancy reviva sua expulsão da Vila do IAPI, evoque a história de Ceilândia, reconstrua a relação com o Plano Piloto. 0 jingle é exorcizado, ressignificado, esvaziado de seu poder original passando a ser uma simples canção.

O carro Santana encarna o centro das contradições. Seu dono, Zé Antônio, é o especulador imobiliário que vive da expansão do urbano aproveitando-se dos efeitos da arquitetura excludente de Brasília. Ganha dinheiro com a especulação mas ajuda, também, seu cunhado Dildu a se eleger pelo Partido da Correria Nacional.

OSantana é por onde as imagens de Brasília e de Ceilândia surgem. OSantana roda nos viadutos, nas entradas e saídas, nas tesourinhas, nas passagens de nível, nos túneis, nos anéis, nos balões. O carro percorre as vias da capital federal como num labirinto, avança, recua, tenta, erra. Uma das características centrais do filme não é a de ser um road-movie, mas um filme-movimento-orgânico ${ }^{3}$ que percorre de carro, de ônibus, a pé, os longos caminhos, as distâncias que separam o plano piloto e Ceilândia. Perdidos no emaranhado de vias de Brasília, Dildu diz: "Que Z, W, eixo central... que negócio é esse?" E acrescenta: "morreu muita gente ali, isso aqui é amaldiçoado...".

Zé Antônio, rodando com seu Santana por Ceilândia, constata a mudança: "era só alface, tomate, agora é tudo lote... não tinha nada aqui, ol ha a chácara do pai do Ivan o que virou: Iotes e casas. Isso aqui era só brejo, o povo criava uns gado aqui, uns cavalo doido, agora olha só, o cara enfia uma casa aqui, um beco, tudo torto". A especulação imobiliária se associa a uma imagem de cidade em expansão permanente, que não pára de crescer, engole tudo ao seu redor, sintetizada na frase de Zé Antônio: "o povo queré morar...".

Numa propaganda de 1972, em plena ditadura militar, Brasília é apresentada como síntese da nacionalidade e o locutor diz: "Brasília espera por você!". Dildu rebate: "será?". Dildu é candidato a deputado distrital pelo PCN, Partido da Correria Nacional. Distribui seus santinhos nas ruas, nos ônibus e sua proposta de campanha
3 | Uso aqui "orgânico" no sentido de que as deambulações dos personagens no filme seguem as lógicas dos fluxos, percursos e movimentos estruturados pelas vias, vielas, que permitem as entradas e saídas seja do Plano Piloto, seja de Ceilândia. Procuro acentuar, assim, que estes deslocamentos estão intrinsecamente integrados ao filme e formam mesmo sua estrutura narrativa. Deste modo, "orgânico", aqui, não tem a conotação atribuída por Deleuze (2005: 123) a um regime imagético cinematográfico que se apoia numa concepção de movimento referida ao que se denomina de "cinema clássico". 
éa indenização para os antigos moradores do Morro do Urubu e Curral das Éguas que foram removidos para Ceilândia.

O X que marcava os barracos na Vila do IAPI é recriado, hoje, como antídoto. Aparece, agora, na camiseta do candidato a deputado Dildu. Reverte seu sentido dizendo que Brasília sem os satélites é "um fantasma", "a cidade pararia sem as pessoas que vem de Ceilândia" e, acrescenta, "mas a gente não tem valor".

Acompanhamos Dildu nos seus longos deslocamentos de ônibus para o trabalho de faxineiro em um colégio. Enquanto dorme no banco do ônibus ecoa a propaganda ufanista sobre Brasília: "vai se irradiar para o norte, para o centro e para o sul, a construção de estradas vitais".

Dildu, caminhando num enorme terreno baldio de terra batida, em que se vê ao fundo o Plano Piloto, prédios em ângulos insuspeitados, a catedral, o Congresso Nacional, pergunta: "o que é aquilo? Um forno de biscoito? Um pão de queijo?".

Entre uma "correria" e outra Dildu come um pastel e toma um caldo de cana. Mas não deixa de sonhar com sua carreira política. Marquim passa a ser o produtor da campanha de Dildu e o ajuda na formatação de sua proposta política e na criação de um jingle "gangster": "Vamos votar, votar legal, 77223 pra distrital. Dildu! (ouve-se sons de tiros)".

Dildu grava sua mensagem-proposta: "vamos acabar com a senzala... você que levanta cedo pra ir pro plano... cinema de um real na praça, filme de bang-bang, filme de amor, filme de caratê... vamos dar um tombo nas asas, moradia popular... acabarcom a hereditariedade no serviço público... botar a favela pra aprender, pra virar classe média cabulosa, cara de favela, caboclo comum, morro do urubu".

Na caminhada por Ceilândia, ao final do filme, Dildu encontra a carreata da candidata à presidência Dilma Rousseff na eleição de 2010, que visita Ceilândia. Escutamos ojingle de Dildu que continua a ecoar como potência alucinatória, porém possível, do Partido da Correria tomar o poder e configurar novos espaços e territórios no planalto central.

\section{ADIRLEY, “O SPIKE LEE DA CEILÂNDIA"4}

O cinema de Adirley Queirós estrutura-se a partir de uma cena etnográfica. Parte do biográfico, das relações pessoais, subjetivas e acede ao propriamente etnográfico, àquilo que entendemos como crítica cultural ou construções contestatórias de mundos sociais. Seu cinema advém de relações de pertencimento, de aderência à visão de mundo do que se pretende tornar "crítico" no plano das imagens. Nesse sentido, o cinema de Adirley Queirós e a etnografia repousam, essencialmente, na constituição de uma relação como gênese, possibilidade de uma narração. Epistemologia que aproxima o etnográfico e o fazer fílmico que ao transpor o real para imagens problematiza questões centrais como o lugar do sujeito, do objeto, da subjetividade, 
da objetividade, do real, do ficcional, da alteridade na produção de conhecimento 5 .

Desde seu primeiro curta, Rap, canto da Ceilândia (2005), até a trilogia composta pelos longas A cidade é uma só? (2011), Branco sai, preto fica (2014), Era uma vez Brasília (2017) seu cinema se constitui como variações ou transformações sobre um mesmo tema: a constituição da cidade de Brasília e suas contradições. Os filmes se realizam, fortemente, como produções colaborativas construídas na vizinhança e na partilha entre os participantes que projetam no filme seus laços históricos e culturais com Ceilândia, transformados numa consciência imagetificada. Esta capacidade imaginativa elaborada por processos de intimidade, conflito, contradições é o que nos reenvia à cena etnográfica, ponto de vista critico à Brasília, que ao destruir (literalmente no filme) o plano piloto por incêndio ou bombardeio acaba por dar lugar a novas visões possíveis.

Adirley Queirós chegou à Ceilândia com a idade de três anos quando seus pais compraram um modesto lote na região. Esta vivência em Ceilândia, local em que estuda e atua, por 10 anos, como jogador de futebol profissional da terceira divisão ${ }^{6}$, produz sua percepção de Brasília. Aos 28 anos, quando sofre uma grave contusão que impede sua continuidade na carreira do futebol, reorienta sua trajetória em direção à Brasília, quando ingressa no Curso de Cinema da Escola de Comunicação da UNB.

Um evento marcou seu desejo de cursar a universidade: jovens conversavam na rua em Ceilândia quando ocorreu uma batida policial, o único liberado foi um rapaz que apresentou a carteira de estudante da UNB. Queirós percebeu, neste momento, que ser estudante universitário funcionava como valorização dos jovens da periferia. Escolheu o curso de cinema porque, à época, era o que tinha a nota de corte mais baixa (Ramos, 2014: 17-18).

Na universidade tem um encontro marcante com a professora Dácia Ibiapina que o ajuda a construir seu primeiro filme, sendo a partir desta experiência que funda o Ceicine (Coletivo de Cinema de Ceilândia), que passa por várias configurações, 'rachas' e 'cismas' motivados pela concepção de política a que os filmes deveriam se associar. Queirós é contrário a rotulações do tipo "discurso político da periferia" por desejar ultrapassar esta barreira que implica em produzir filmes menos de 'cartilha', mais "experimentais, não óbvios", sair do 'politicamente correto", da 'pobreza', temas que orientam a construção de editais voltados para a chamada cultura periférica (Ramos, 2014: 19).

"Brasília é uma ficção, podia muito bem ser um holograma pois sempre se está de passagem pela cidade, as pessoas não frequentam Brasília, a conhecem através da janela do ônibus" e "Brasília é uma ilusão" (Queirós apud Ramos, 2014: 15, 56), são reflexões de Queirós que enquadram a percepção de um espaço político-sócio-territorial distendido entre Brasília e as cidades satélites ao mesmo tempo que declaram o combate, intenção de seus filmes, que se dará no plano, justamente, do esgarçamento da ficção, da ilusão e do imaginário.

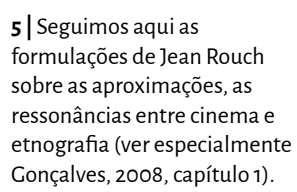
ressonâncias entre cinema e etnografia (ver especialmente Conçalves, 2008, capítulo 1).

6| Tema que foi abordado em seu filme Fora de campo (2010) em que retrata biografias e histórias dos jogadores dos clubes de terceira divisão do Distrito Federal. 
Seus filmes resistem ao senso comum que associa Ceilândia à violência, à periferia, a "lugar ruim", revelada por um imaginário na relação incontornável com Brasília (Ramos, 2014: 8). Reconfiguram a ideia de violência ao inverterem o sentido do vetor que passa a fluir do plano piloto em direção a Ceilândia, pondo em foco uma violência histórica e social que parte do centro em direção à periferia (ibid: 26) .

Rap, o canto da Ceilândia (2005), é um filme canônico a partir do qual seu cinema será expandido em mais 4 filmes firmando o coletivo de cinema Ceicine. Neste primeiro filme o rapper Marquim (ator dos demais filmes) evoca a história da formação de Ceilândia, das remoções da favela do IAPI, da Campanha de Erradicação de Invasões, esboçando uma configuração do que significa plano piloto e a formação das cidades satélites. O filme apresenta imagens fotográficas antigas do IAPI, imagens de Ceilândia hoje, depoimentos de pessoas que testemunham o transplante populacional, o desterro como processo autoritário urbanizador que acaba por criar o mito de Ceilândia como "terra de bandido", "flagelo de guerra"7. Porém, encontram-se, também, neste primeiro filme os possíveis reviramentos de sentido sobre Ceilândia, novas ressignificações, quando dizem, por exemplo, "sou negão, careca, da Ceilândia e daí?", "a gente mora aqui é ébom, mesmo sendo ruim, a gente fala que é bom". Ceilândia passa a ser definida como lócus do encontro entre o preconceito racial e o territorial, tendo como pano de fundo Brasília, espécie de "muro que separou os pobres dos ricos".

Dias de greve (2009), inspirado em um conto de Albert Camus, é o seu segundo curta. Um grupo de trabalhadores experimentam, durante os dias de greve, um outro cotidiano marcado pelo lazer, como soltar pipa, jogar futebol, trabalhar no barracão da escola de samba, tomar cerveja, consertar o carro, conversar com os amigos. A greve não dá certo e são obrigados a retornar à fábrica, voltando a viver a opressão do mundo do trabalho. O filme, em seu final, apresenta o desfile da escola de samba no sambódromo de Brasília em que se celebra uma "união" entre empregados e patrões, que cantam e dançam o samba enredo, tendo como desfecho a tomada de consciência de classe e da exploração, quando um dos empregados que desfila estranha seu processo vivido no carnaval e, distanciando-se da cena, caminha melancólico pela avenida.

Fora de campo (2010) retrata o mundo, invisível para o grande público, dos mais de 500 clubes profissionais de futebol que atuam no Brasil sendo que apenas 40 destes disputam os grandes campeonatos que representam $8 \%$ do total dos jogadores profissionais brasileiros. Este é um filme autobiográfico, que retrata sua vivência e experiência como jogador de futebol. O filme visita e entrevista ex-jogadores, explora seus sonhos como o de jogarem nos grandes clubes, apresentando o estar na "terceira divisão" como o situar-se na periferia, vivendo a exclusão social como a falta da carteira assinada, salários atrasados, o que transforma os jogadores em camelos, enfermeiros, taxistas e pastores.

Branco sai, preto fica (2015) e Era um vez Brasília (2017) expandem ainda mais os
$7 \mid$ As relações entre Brasília e cidades satélites remontam não apenas a história particular de Brasília, mas evocam formas de exclusão e exploração que estão na base da formação do capitalismo e da construção da cidade moderna (Borges, 2009 31). Para uma análise detalhada dos processos de criação de Ceilândia, de suas questões contemporâneas, de sua formação como cidade satélite e sobre sua segregação social e territorial ver, especialmente, Tavares (2012, cap. 4). 
conceitos e os problemas postos pelo A cidadeé uma só? Radicalizam as configurações da exclusão sócio espacial de Ceilândia, apostando em cenários distópicos e futuristas que acentuam os processos de alteração e alteridade propostos pelo cinema de Queirós. Branco sai, preto fica faz o encontro entre a exclusão territorial e a violência racial. Era uma vez Brasília, nos proporciona uma tomada de consciência do momento político contemporâneo pós-impeachment da presidente Dilma Rousseff, cenário catástrofe em que Brasília passa a viver os efeitos "Blade Runner 2016". Imaginário entrópico agigantado que nos projeta no ano 'zero' pós-golpe, pós destruição daquele mundo.

Outro filme, ainda em realização, tem como título "Cartas lacradas": narra mais um episódio das relações complexas entre Ceilândia e Brasília. Cristovam Buarque, no primeiro ano de seu mandato como governador do Distrito Federal, em 1995, pede que as crianças do ensino público de Ceilândia escrevam sobre seu amor por Brasília e como imaginariam a cidade quinze anos depois, em 2010. Queirós localiza, no Arquivo Nacional, as 16 mil cartas guardadas em caixas que nunca foram abertas (Ramos, 2014: 29).

\section{SITIANDO FRONTEIRAS: FICÇÃO/DOCUMENTÁRIO}

"A cidade é uma só?" surge a partir de duas aposições de sinais que invertem o significado original da frase e o da própria concepção de Brasília. O sinal de interrogação ao final da frase-título, que coincide com o jingle original de 1970 e o X sobreposto à imagem do plano piloto, imagem ícone do filme, cujo significado nos reenvia à marcação das casas na vila do IAPI que deveriam ser removidas. O X significou a remoção de 80.000 pessoas, média de 300 por dia, em um período de 9 meses, que foram transferidas para Ceilândia (Ramos, 2014:25): topônimo motivado que dava 'posse' aos removidos a uma nova configuração territorial. O X é, também, uma torção do símbolo da 'cruz', primeiro risco no papel dado por Lucio Costa que deflagra o projeto original de Brasília. O X sobreposto ao plano piloto anula a cruz como modo de possessão de Brasília surgida no seu traço inaugural.

A cidade é uma só? começa a ser filmado com verbas oriundas de um edital que celebraria os 50 anos de Brasília. A ideia inicial era contar a história de Nancy Araújo, girando em torno de sua memória sobre o episódio do jingle propaganda, cantado pelas crianças da vila do IAPI, que anunciava a remoção destas famílias para Ceilândia no começo dos anos 70. Queirós deu uma guinada no roteiro do filme quando percebeu que a narrativa de Nancy se voltava mais para um público intelectual e de cinema do que para as pessoas da própria Ceilândia. Classifica esta narrativa como "xaropada" e "reacionária", não no sentido pejorativo que estes dois termos podem ter, mas por ter criado uma espécie de "mito de origem oficial de Ceilândia". Queirós reflete sobre a narrativa de Nancy, dizendo: "a memória da gente é o primeiro lugar que deve ser combatido, porque há uma idealização do passado, e esta desconstrução da memória 
deve ser sempre feita para uma narração, senão vira uma narração reacionária" (Queirós, 2017). Acrescenta: "O personagem politicamente correto no cinema é reacionário. Na política ok. Mas no cinema não dá”. (Queirós, 2015a).

Resolve, portanto, convidar Dildu e Zé Antônio para que atuem no filme de um modo espontâneo, com a intenção de criar uma atmosfera "popular". Desta intervenção surgem diversas improvisações, narrativas sobre a especulação imobiliária e a política em Brasília, culminando na mise-en-scène da criação de um partido político, o Partido da Correria Nacional, pois o ano de 2010 coincidia com a eleição presidencial (Queirós, 2017).

Nancy criava um mito sobre Ceilândia que deixava em segundo plano uma Ceilândia que, na percepção de Queirós, era "muito ruim, faltava tudo, água, tinha epidemia de meningite, tinha que se combater esta memória idealizada da Nancy". Aprofunda esta discussão retirando dela as lições para o documentário em geral ao afirmar que o difícil neste gênero é pôr em contradição aquilo que se gosta, sendo necessário humanizar uma pessoa que se idealiza. Para Queirós, por mais que seja possível construir os personagens como heróis, como 'Marvel', sua humanidade deve ser revelada, implicando em explicitar contradições (Queirós, 2017).

Continuando sua linha de raciocínio, reconhece que para realizar um bom filme não é necessária uma "convivência" ou um "conhecimento" sobre o que se quer abordar, mas sim uma explicitação das contradições do processo: "é uma bobagem pensar que a pessoa tem que morar em Ceilândia para fazer um filme bom em Ceilândia, não tem nada a ver, a questão é enfrentar as contradições. Mas o cinema brasileiro hoje pensa deste modo. É um erro isso, você pode ser de marte e fazer um filme muito bom em Ceilândia". Levando ainda mais longe seu pensamento, o cineasta nos diz que "não existe filme bom, existem 4 ou 5 filmes bons, os filmes ruins são a média" e, neste sentido, o que importa seria realizar um filme "honesto". Isto é, um filme que 'mobilize' as pessoas e por isso os filmes honestos devem ser, necessariamente, "violentos". Exemplifica: "durante quatro meses andando de carro por Brasília, filmando, eu e os personagens do filme acreditávamos que íamos botar fogo em Brasília” (Queirós, 2017). Do mesmo modo, para Queirós, "coletivo" não significa algo harmonioso, mas sim contraditório e é neste sentido que afirma que seus filmes surgem de embates de ideias entre os participantes, sendo o cinema, ele mesmo, lócus da disputa, em que a "raiva" é uma qualificação importante e presente no processo cinematográfico (Queirós, 2013).

Uma vez que seu cinema se estrutura pela crítica à "territorializações" recusa ocupar este espaço "naturalizado" da periferia como forma de apresentar uma visão de mundo. Esta condição de "ser outro" para produzir uma visão crítica e contraditória faz o seu cinema operar numa radicalidade do conceito de alteridade, produzindo uma dessubstancialização de identidades e de espaços (Queirós, 2017).

Para Queirós, a alteridade é crucial no processo de produzir imagens e reflexões sobre o mundo. Aportamos aqui em sua máxima quando nos diz que Ceilândia "pulou

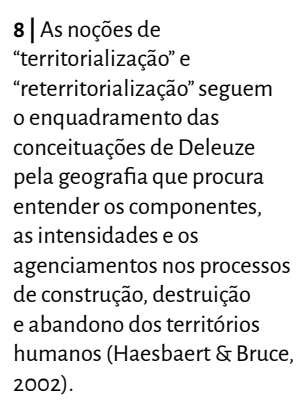


pra dentro dele quando ela virou filme", quando visualizada enquanto imagem. Foi Ceilândia filmada, "aquela alteridade", que permitiu um estranhamento, uma alteração de sua percepção de familiaridade, o que o impulsiona a produzir uma reflexão. Retorna, assim, à questão da localização, da presença, da autenticidade discursiva, da auto representação que passa, sobretudo, pela alteridade, pela reflexão, pelo estranhamento como modo de conhecimento que engendra, por isso mesmo, "a quebra gramatical" de que nos fala e aquilo que o faz estranhar/criar um novo cinema, uma nova cidade e uma nova gramática das imagens que passam a ser o meio reflexivo sobre o mundo mediadas e constituídas pelo processo que define como alteridade ${ }^{9}$ (Queirós, 2013). Deste modo, Queirós “sitia” as fronteiras, sua câmera não sai de dentro do carro que circula, não deixa, deliberadamente, a arquitetura ganhar a cena mas sim seus personagens e seus pontos de vista sobre Brasília.

Um outro elemento que ajuda a sitiar as fronteiras entre documentário e ficção é o uso deliberado de distintas temporalidades acionadas pelos próprios personagens do filme que, por sua vez, não produzem "passado" e "presente" mas camadas temporais-significacionais responsáveis por projetar o filme como aguda crítica atemporal ao lugar do "moderno" na formação nacional. Brasília, assim, é construída como alegoria dos processos de exclusão que ocorrem nas grandes cidades brasileiras.

Para Queirós, Nancy encarnava o paradoxo de ser a única pessoa de verdade no filme, embora fosse a que mais representasse. Dildu e Zé Antônio eram atores mas pareciam ser os mais verdadeiros (Queirós, 2017). Retornamos, aqui, ao problema clássico da ficção e os domínios da "verdade" e da "farsa", os quais Queirós pretende desconstruir uma vez que coincide com a questão fundadora de seu cinema.

A percepção de ir além da oposição ficção/documentário é explicitada por Queirós (2012) quando compreende que o documentário não é nem o real e nem a farsa, mas a possibilidade de sitiar - e não situar - a fronteira entre os chamados regimes documental e ficcional. Este "sitiar" a fronteira se constitui enquanto modo de pôr em questão não apenas a barra que separa ficção/documentário, mas interrogar, estruturalmente, a própria razão ocidental fundada nesta oposição como operadora de narrativas que produzem divisores de mundos, conceitos e ideias. Queirós segue, neste ponto, princípios de cinemas outros, que 'sitiam' fronteiras, não apenas do cinema mas do próprio pensamento, como modo de nos dar a ver novos problemas e novas questões.

Documentário e ficção para o cinema parecem ser da mesma ordem das categorias de natureza e cultura para a antropologia (Descola, 2006). Separações que evocam problemas do racionalismo cartesiano e suas dualidades. Do mesmo modo que natureza e cultura foram problematizadas por outros pensamentos, o cinema, quando se constrói, com e através de um álter, pode alterar sua percepção do que seja ficção e documentário e mesmo superá-la ao ensejar uma crítica que proponha uma nova ordem discursiva que não se funda mais por oposições estanques e estabelecidas
9| "Alteridade" passou a ser uma "categoria nativa" na linguagem dos documentaristas. Foi cunhada por Eduardo Coutinho como a essência do documentário (Coutinho, 1997) ao procurar explicitar a importância da reflexividade sobre a relação com o outro e o lugar que o outro ocupa nas narrações do real. Ver, especialmente, Batista (2018) sobre o rendimento da categoria de alteridade para se pensar 0 documentário moderno e o cinema de Adirley Queirós. 
do pensamento ocidental. O cinema de Queirós desloca o problema do real ou do ficcional para um outro plano, agora capaz de quebrar, via a alteridade e sua conceituação, a gramática formal dos discursos narrativos da ficção e/ou do documentário.

É neste sentido que Queirós realiza um cinema visceral em que outras categorias afloram como as de corpo e "correria" que embaralham fronteiras estabelecidas. Seus filmes se estruturam pela pregnância do corpo, um modo de operar imagens que remonta a sua experiência juvenil no único cinema de Ceilândia cujas sessões de "sexcaratê" exibiam filmes pornôs, de Bruce Lee e alguns faroestes.

Um dos argumentos centrais de seu cinema é a ênfase nos processos corporais, seja o próprio corpo, seja um modo de encorporação da história narrada. Para Queirós a dramaturgia é o que o corpo expressa: "seu tempo de fala, sua caminhada, a preguiça, a má vontade” (Queirós, 2013). Em seu filme Branco sai, preto fica o corpo amputado torna-se sinédoque da cidade amputada. O corpo enquanto memória de luta, sobrevivente de enfrentamentos, não pode ser reduzido a uma condição de mártir ou sofredor, uma vez que, em sua concepção, o próprio imaginário do cinema é capaz de empoderá-lo produzindo um corpo cinematográfico como corpo de combate, de luta.

Queirós, ao assumir seu pertencimento à Ceilândia, estimula os atores a deixarem emergir um cinema que advém, sobretudo, de seus corpos. Corpos periféricos que expressam determinadas características como "um jeito corrido e nem sempre claro de falar", um modo de andar, um gesticular. Revelar este "corpo periférico" é, na sua percepção, assumir sua beleza, valorizando-o, mostrando-o na tela (Ramos, 2014: 11). Ao invés de apagar marcas corporais não normativas do cinema hegemônico, procura-se acentuá-las como demarcações de espaços territoriais e políticos revelando uma ênfase em um cinema radicalmente corporal que nos dá a ver como "a cidade é internalizada no corpo do ator" (ibid:28).

A perspectiva corporal de seus filmes pode ser acessada a partir de um conceito fundado n'A cidade é uma só?, que é o de "correria". Correria em sua forma política expressa um modo subjetivo do corpo se engajar e ser engajado nas lutas, nos combates pela sobrevivência, um corpo em movimento, um corpo que está "correndo atrás". A formulação de um Partido da Correria Nacional é a proposição conceitual nativa para um cinema visceral, corpo subjetivo e político, simultaneamente.

O corpo "ocupa" o cinema de Queirós com sua voz, sua fala, sua história, seu movimento. O corpo ganha centralidade na tela, impedindo, assim, que no seu cinema emerjam classificações esquemáticas como as de verdade, falsidade, réplica, real, ficção, documentário. As questões evocadas pelo cinema de Queirós sobre corporalidade apontam para o lugar central do corpo no cinema. Acentuam, assim, as proposições que pensam a importância do gesto (e não apenas da imagem) como modo de expressão de um pensamento-ação corporeificado que, por sua vez, produz um deslocamento de um regime imagético apoiado na visão/olhar para outro baseado no sensorial/corporal (Deleuze, 2005; Macdougall, 2006). 


\section{ANARQUITETURA, SEQUESTRANDO ESPAÇOS}

A cidade é uma só? apresenta uma concepção de anarquitetura, anarcoplanejamento como modo de produzir Ceilândia, desafiando, assim, as ideias modernas que constituíram Brasília. Queirós desestabiliza uma narrativa sobre Brasília construída a partir do lugar de poder, de Juscelino, dos arquitetos (Queirós, 2015b). Anarquitetura e sequestradores de espaços são figuras de linguagem e de ação que melhor representam A cidade é uma só? Associando anarquismo à arquitetura, realiza uma crítica aos planejadores urbanos e aos arquitetos, questionando os espaços projetados e a "cultura hierárquica da arquitetura".10

Brasília operou, através do espaço, uma entrada política triunfal do Brasil na modernidade. Sua localização e sua arquitetura marcam um rompimento com a forma Brasil-colônia ao se afastar das "feitorias-cidades" do litoral. Conquista o interior por meio de um arrojado projeto urbanístico que figurava um novo imaginário do Brasil, agora urbano, moderno, industrial, pretensamente igualitário. Entretanto, Brasília encontra suas próprias contradições cristalizadas nas insurgências das cidades satélites, nódulos produzidos pelo modernismo excludente, que forçam uma reperspectivação de seu projeto urbanístico-social.

Passados 13 anos da fundação de Brasília, a visão do criador sobre a criatura torna-se consciente. Lucio Costa (1973) via na construção de Brasília um projeto de nação que se desenhava sobre os esboços modernos da industrialização e o abandono definitivo da arquitetura colonial ou imperial em que era preciso superar um modelo social de um Brasil rural, escravocrata e exportador, em favor de uma utopia criadora e redentora.

Numa definição sintética proposta por Almino (2007:301), a falta de história de Brasília contrasta com seu imaginário representacional: "E o que Brasília simboliza? A democracia. A racionalidade. A nação. A integração e o desenvolvimento. A aspiração de igualdade. O moderno. O futuro. E também, claro, o poder, a alienação, o encastelamento, a corrupção, o autoritarismo, o misticismo e a irracionalidade".

Brasília revivia, através do projeto modernista, a mitologia do Novo Mundo, uma nova utopia morrusiana: "... a construção de uma capital no Planalto Central seria o meio de desencadear o florescimento de uma grande civilização num paraíso de abundância... instituir um novo sistema de vida" (Holston, 1993: 23). Produto do encontro entre "ascéticas e racionalizadas utopias" e as injustiças da realidade social (Stenzel, 1993:187-188), a cidade modernista nasce pós-moderna: anula a história, leva o Brasil ao futuro, decreta a "morte da rua", encerra a forma colonial de sociabilidade brasileira, produz a ideia do Estado como o operador e organizador da vida social"1.

Hoston (1989 e1993) nos fala de uma crença arquitetônica modernista em que seria possível uma cidade surgir como reflexo de um mundo imaginado. $O$ desenho daria concretude à concepção utópica no plano do urbanismo de uma sociedade
10| Estes conceitos são aprofundados especialmente em Attle (2007). O autor discute a obra de Gordon Matta-Clark que, desde 1973, produziu uma reflexão crítica sobre a arquitetura, desconstruindo seus princípios modernistas, tendo como ponto de inflexão a obra de Le Corbusier. Matta-Clark transforma Vers une architecture (1922) em Vers Anarchiteture (1974). Anarquitetura foi defina por Matta-Clark como "fazer espaço sem construí-lo" ou como "a celebração da cidade em toda a sua desordem,

variedade, justaposição louca de eras e estilos". Ver, também o Manifesto dos Space Hijackers and Anarchitects (https:// spacehijackers.org/html/ manifesto.html - último acesso em 18/09/2018)

11 | Ver, especialmente, Koolhaas para uma crítica ao projeto modernista de Le Corbusier e a sua comparação ao Método Crítico Paranoico desenvolvido pelo modelo surrealista de Salvador Dali. Neste contexto, a arquitetura surge como "a imposição no mundo de estruturas nunca antes solicitadas, existindo anteriormente apenas como nuvens de conjecturas nas mentes de seus criadores" (1994: 248). 
igualitária e de um "bom governo". Uma "filosofia da cidade" ancorada na ideologia do urbanismo e da arquitetura pós Le Corbusier, em que o arquiteto "percebe a si mesmo e se concebe como Arquiteto do Mundo, imagem do Deus criador"12 (Lefebvre, 2001: 48).

Brasília inaugura, assim, uma era da arquitetura que formulava para os problemas sociais soluções racionais, planejadas, tomando o espaço como instância central de ordenamento. Espírito modernista ainda hoje dominante, em que os projetos para a sociedade brasileira advêm de maquetes, plantas baixas. Ao cultivar premissas da "terra arrasada", do começar de novo, da negação da história, gera futuros incertos situados "fora do plano" dos arquitetos, urbanistas, idealizadores. ${ }^{13}$ Estes modos de proceder, por vezes tão redentores quanto autoritários, deram vida ao traçado de Brasília que se inspira, como vimos, não por coincidência no símbolo da cruz: "quem assinala um lugar ou dele toma posse: dois eixos cruzando-se em ângulo reto, ou seja, o próprio sinal da cruz" (Costa, 1991: 19). Esta significação nos reenvia à conquista de um território, remontando ao primeiro símbolo, fincado em solo brasileiro quando da primeira missa rezada em 26 de abril de 1500 em Santa Cruz Cabrália, litoral sul da Bahia.

A figura geométrica de Lucio Costa não pretende ser a cruz da primeira missa, mas não deixa de ecoar um modo de operar uma apropriação do espaço a ser configurado em território, efeito de colonização que lhe imprime uma história.

Do mesmo modo, a aguda percepção de Andrade ${ }^{14}$ sublinha que o Palácio do Planalto, mesmo com todo o artifício dos arquitetos, não escapa da forma arquitetônica que está remetida a uma casa de fazenda, com varandas em volta e uma capela lateral, apontando como o "moderno" e o "novo" se escondem na casa grande, cuja forma arquitetônica-social reflete uma estrutura de poder.

Em artigo pioneiro Pfeiffer detectava o fenômeno que designa de o "nascimento das favelas de Brasília" (1964: 392). Em 1964 Brasília tinha 200.000 habitantes, dos quais apenas 80.000 conseguiam morar no Plano, o restante habitava "acampamentos temporários" ou vivia nas cidades satélites, apartadas, às vezes, por uma distância de $40 \mathrm{~km}$. Percebe as contradições entre os princípios da Novacap ${ }^{15}$, que dava surgimento às cidades satélites baseadas em decisões políticas e não urbanísticas, e o plano original estabelecido pelos urbanistas e arquitetos. Nesse contexto, a criação da Novacap instaura uma política de repressão exercida contra os trabalhadores, capaz de regular e ordenar as inquietações e os conflitos surgidos a partir de demandas de melhoria de vida no começo das chamadas "invasões", o que se modelava como um embrião do que Brasília se tornaria no futuro (Ribeiro, 2006).

Lucio Costa reconhece os "pontos forçados" de Brasília, aquilo que seus habitantes criaram como o centro comercial em torno da rodoviária, dando-se conta que a vida da cidade transforma os "planos", levando-o a afirmar que "o sonho foi menor do que a realidade e que a realidade foi maior e mais bela" (Costa, 1991). Reconhece, assim, a "urbanização desurbanizante e desurbanizada" (Lefebvre, 2001: 25), tensão
12 | Lefebvre (2001: 54-63) faz uma distinção importante entre cidade e urbanismo, distinção que permite compreender a construção de Brasília e seus processos de tornar-se uma realidade social, que vai além de um desejo criador estabelecido na ordem do pensamento.

13 | Ver Yaneva (2012: 2-4) sobre as premissas da arquitetura moderna, enquadradas, mais amplamente, no pensamento moderno e suas epistemologias que pressupõem concepções bifurcadas e "divisores" de toda ordem, que se rebatem de modo importante sobre a construção do espaço arquitetônico moderno. Yaneva segue, em sua proposição crítica, os argumentos de Latour (1993) sobre a construção da modernidade.

14 | Joaquim Pedro de Andrade percebe esta forma arquitetônica quando filma os palácios de Brasília para o seu filme Brasília contradições de uma cidade nova (1967).

15 Companhia Urbanizadora da Nova Capital, criada em 1956 com o objetivo precípuo de construir Brasília. 
própria da construção arquitetônica da cidade no seu dia a dia, e sobretudo o que silencia, o que deixa fora do "plano", princípios não conciliatórios, as chamadas "invasões", que projetavam no espaço as contradições que vieram a se materializar como cidades satélites (Holanda, 1989: 82).

A cidade é uma só? se distancia de um esquema maniqueísta entre o moderno e o antimoderno ${ }^{16}$, Brasília e Ceilândia. Adirley Queirós ao produzir um cinema a partir do vivido, do percebido e do concebido nos apresenta as tensões entre um "moderno imaginado" e um "moderno excludente". Ao "sequestrar o espaço" de Brasília, incinerando cinematograficamente o plano piloto, destrói, desde o início do filme, a proposta estrutural do desenho modernista. Propõe um grau zero das imagens para daí em diante evocar uma nova possibilidade para a existência de Brasília, que inclui, definitivamente, Ceilândia. Este aspecto da destruição como proposta criativa é expressa por Queirós justificando a intenção do filme: "Daí eu pensei em como fazer um filme agradável, legal e gângster: Brasília, I love you"."17

Brasília é uma cidade que nasce da imagem, não apenas dos desenhos, dos croquis, mas dos planos do cinema. Documentada, pela primeira vez, por Jean Manzon em As primeiras imagens de Brasília, 1956/57, que apresenta de forma harmônica os operários na construção frenética da cidade, revezando-se em turnos dia e noite, tomando banho em chuveiros improvisados, em contraste com os políticos e arquitetos que circulam pelo canteiro de obras de terno e gravata ou em ambientes envidraçados. Imagens que naturalizam o projeto utópico moderno. O fotógrafo Gautherot (1960), ele mesmo arquiteto e atuando sob grande influência estética do modernismo, ressalta a grandiosidade e o aspecto intelectual da invenção e criação de Brasília. Suas fotografias ecoam a frase de Lucio Costa: "Brasília, a cidade que inventei" (Costa, 1991).

A cidade é uma só? não inaugura um contradiscurso sobre Brasília. Ao contrário, segue uma tradição documental contestatória que desde a década de 1960 nos dá a ver as contradições do moderno em Brasília ${ }^{18}$. Trato, a seguir, de alguns destes filmes procurando estabelecer suas ressonâncias com o cinema contemporâneo de Adirley Queirós, de modo a perceber como imageticamente foi composto o chamado imaginário da cidade de Brasília e das cidades satélites.

O filme de Joaquim Pedro de Andrade, Brasília contradições de uma cidade nova (1967), entrevista pessoas que foram removidas da Vila do IAPI para Taguatinga, mostrando barracos destruídos e a violência das remoções. O filme tem como argumento central demonstrar a desigualdade social de Brasília, cidade que reproduziria as mesmas questões de outras brasileiras: exclusão social transposta para o plano territorial.

Andrade coloca em prática a mesma mise-en-scène que A cidade é uma só? ao adotar o ponto de vista do movimento, da circulação pelo plano piloto, pelo eixo monumental, as grandes avenidas, as quadras. Andrade situa a câmera voltada para fora do carro captando, num primeiro momento, imagens que projetam a arquitetura de Brasília como protagonista. $\mathbf{1 6}$ | Ver, especialmente, a problematização do "moderno" proposta por Schwarz que enfatiza, sobretudo, os impasses do processo de formação nacional que se situam justamente no modo como o "moderno" é explicitado sendo, ele mesmo, uma espécie de "implicação estrutural" no modo de pensar o Brasil. Menos que dualismo entre "atraso" e "moderno" Roberto Schwarz vê estas categoriais como modos de articulações em conjunturas específicas (Schwarz, 2000 e 2012).

17| Fala de Queirós na primeira exibição pública do filme, Festival de Tiradentes, 2013.

18 | Brasília segundo Feldman (1979), de Vladimir Carvalho e Eugene Feldman, faz um registro inédito durante sua construção. $\mathrm{O}$ americano Feldman apresenta imagens coloridas e raras dos primeiros tempos de Brasília. Fala Brasília, 1966, de Nelson Pereira dos Santos trata da diversidade dos sotaques e falas dos migrantes do Distrito Federal, reverberando as vozes e culturas do Brasil. As pessoas expõem o seu sotaque, suas vidas, suas experiências e seus sonhos. Para uma análise detalhada dos filmes sobre Brasília entre 1956 a 2014 . que colocam em evidência as contradições da utopia arquitetônica modernista, ver Lima (2016). 
Andrade aponta para a contradição estrutural de Brasília posta em termos de uma oposição entre arquitetura e ornamento, a concepção do arquiteto e o gosto do morador $^{19}$. A câmera sai do plano piloto em direção aos seus extremos, onde se encontram os cemitérios e as novas estradas que conectam as cidades satélites. Saímos do projeto arquitetônico e adentramos no espaço da desigualdade social e urbana. $O$ filme alcança os dois terços da população de Brasília que está situada fora do plano, incluindo aí os próprios operários que construíram Brasília. Imagens das filas para pegar os ônibus lotados que, depois de três horas de viagem, chegam ao seu destino final nas cidades dormitórios: vilas com pequenas casas, grandes feiras "nordestinas" que desafiam as linhas equilibradas do plano piloto. Ouvimos um depoimento de uma mulher que narra a remoção realizada por caminhões basculantes. Em um ônibus repleto de migrantes nordestinos que vão "tentar a sorte" em Brasília, plano final do filme, uma mulher diz: "não sei se vai ser bom ou se vai ser ruim".

$\mathrm{O}$ arquiteto Oscar Niemeyer procurado por Joaquim Pedro de Andrade quando o filme foi censurado em 1967, acreditava na capacidade de transformação social que a arquitetura poderia engendrar. Imaginava que, passado o regime militar, Brasília cumpriria seu papel de socializadora das diferenças em que ministros de Estado e empregados habitariam a mesma superquadra e seus filhos iriam para o mesmo colégio ${ }^{20}$.

Em Conterrâneos velho de guerra (1991) de Vladimir Carvalho, Niemeyer constata que o sonho de realizar uma cidade do futuro não se realizou: "Vejo meus irmãos operários afastados daquilo que construíram e nunca poderem usufruir da cidade. Retornam ao seu lugar de origem mais pobres do que chegaram ou vão morar nas periferias, vendo Brasília de longe, como um sonho frustrado". Esta fala de Niemeyer é pontuada pela de um operário: "Os funcionários públicos, tinham total mordomia e nós não ganhamos nada. E tudo que construímos parecia que era nosso. A mudança do IAPI, remoção, deixar a capital livre para os turistas. Remover pra Ceilândia, para o mato, jogados aqui como animal brabo... não conseguimos ficar em Brasília, enfeávamos a cidade, mas nós construímos a cidade".

A cidade é uma só? não percebe Ceilândia como utopia modernista não realizada em que ocuparia o espaço da heterotopia, do desvio, do lugar dos excluídos (Foucault, 2013 apud Lima, 2016). O filme, ao contrário, dá a ver um espaço insurgente, contraditório, ao expor imaginários a partir de movimentos reais entre Brasília e Ceilândia. Portanto, Ceilândia dá existência ao filme, outros "planos" ressignificam Brasília como múltipla, heterogênea, desigual, multifacetada, complexa, longe da ficção normativa dos arquitetos.

Brasília não é apenas uma cidade do futuro, ela é futurista: "capital de país que ainda não existe, de uma nação imaginária" (Rizek, 1993: 39 apud Stenzel, 1993: 190).

Cidade sem mundo, sem centro, sem resto, sem periferia, que saída dos planos dos arquitetos sofre impactos nos planos do filme. Ceilândia, sua formação, sua história, irrompe o silêncio transformando as outroras invasões em invasores, o plano em mudança, a fixação em fluidez. Encarna, literalmente, a ideia de satélite como potência
19 | Contradição transposta para a trilha sonora do filme: Erik Satie versus Viramundo de Gilberto Cil e Capinan.

20| Nos anos 1980 Niemeyer reconhece o pessimismo de Joaquim Pedro de Andrade. Realiza que Brasília é, agora, uma cidade como qualquer outra cidade brasileira (Carvalho, 1991) 
significacional do novo espaço "Brasília' criado pelo filme, contestação de espaços que ao retirarCeilândia de Brasília recoloca Brasília dentro de Ceilândia. Reinscreve, assim, presenças subjetivas no plano da história e do próprio filme (Silva, 2015: 79).

\section{EFEITO BLADE RUNNER: ENTROPIA, DISTOPIA ${ }^{21}$}

Queirós (2017) afirma que não tem uma "cultura cinematográfica" ou cinéfila. Reitera que assiste muitas vezes aos mesmos filmes e entre seus preferidos está Blade Runner ${ }^{22}$, filme que assistiu pela primeira vez no Cine Lara em Taguatinga e depois mais 29 vezes em outras sessões de cinema: "Brancosai foi fazer um Blade Runner quebrado" (Queirós, 2014). Seu sonho é o de fazer um verdadeiro "Blade Runner 3" que se passaria em 2071, ano em que Ceilândia completa 100 anos: "Um BR 2071, um esquema meio tora, câmera 16, 10 latas, à noite, com doidão, imbuído naquela história mesmo de um replicante que foge. Aí é um doidão andando, correndo com a câmera 16, alucinado, trash, filme punk. Muita sonzeira, muita correria, muita loucura".

Reconhece que é leitor e admirador de ficção científica, lê Philip Dick mas nos diz que o "melhor livro do mundo" é Crônicas Marcianas de Brady Burry²3: uma visão psicodélica dos dramas do cotidiano que reflete sobre o medo de uma guerra atômica após a Segunda Guerra, que poderia (ou poderá?) dizimar a vida na Terra. Queirós (2017) acrescenta que este livro trata de um tema caro ao seu cinema, a memória: "Iugarque te aprisiona, que talvez, para vocêsubverter a realidade, tem que estourar a memória. A memória é importante para te dar uma identidade, mas se você fica nela, você fica muito aprisionado, vocênão consegue sair, como se ela te desfocasse". Blade Runner e A cidadeé uma só? lidam com a questão da memória, ocupando-se de fotografias que encarnam uma temporalidade essencialmente humana, seres para a vida que contrastam com os "replicantes", seres para a morte (Lussier \& Cowan, 2012:171).

Blade Runner se liga, inexoravelmente, à experiência do crescimento das cidades, do planejamento urbano, da demografia, às formas de ocupação do espaço nas megalópoles. Reflete sobre as incertezas do futuro em uma cidade que se expande infinitamente. A cidade é, portanto, vivida como pesadelo urbano (Rowley, 2005). Blade Runner antecipa, já em 1982, uma série de problemas sociológicos sobre o urbano e os desafios de sociabilidade em mundos pós-humanos (Chevrier, 1983: 138). É preciso acentuar que a discussão sobre pós-modernismo, identidade, história (Bruno, 1987: 62) emerge, como Jameson, admite, da arquitetura e, principalmente, de sua crítica ao modernismo expresso no que veio a se configurar no "estilo Le Corbusier" (Jameson, 1991: 54). Este questionamento arquitetônico permite tornar os problemas teóricos "dramaticamente visíveis" no contexto do pós-colonialismo, pós-modernismo, pós-industrialismo, posmetropolis em que o espaço surge como uma arena de contradições e conflitos.

Queirós, ao construir com seus filmes uma anarquitetura de Brasília, deixa emergir o "efeito Blade Runner", possibilidade imaginativa de recriar estes espaços
21 | Se distopia é o reconhecimento de uma ideia de imperfeição, desespero ou não esperança não a tomamos aqui como algo da ordem apocalíptica, da destruição da humanidade e da sociedade. Pelo contrário, distopia produz uma imagem de um imperfeit porém habitável, desejável e, até mesmo, confortável mundo possível (Conçalves, 2016: 169; Jameson, 2006: 31)

22 | O filme é uma adaptação do livro Do androids dream of electric sheep de Philip Dick escrito no final dos anos 1960 cujo enredo é a história de um detetive em um futuro sombrio que reflete sobre o cenário político social contemporâneo: "manifestações populares, desordem, guerra do Vietnam, movimento hippie, drogas, contracultura, escândalos e a guerra fria" (McKinty, 2018: 2). O título vem do livro homônimo de Burroughs The Blade Runner (1979) e foi uma adaptação para o cinema do livro de Alan Nourse (1974) publicado originalmente em 1974 com o mesmo título (Ardoin, 2015: 63-64). Blade Runner (que transcorre no ano de 2019) limita-se a dois aspectos do livro: visões da megalópole do futuro, com seus edifícios de 400 andares, e a perseguição implacável de um caçador profissional a um pequeno grupo de androides evadidos: "produtos" quase perfeitos, super-homens e supermulheres que aspiram a um pouco mais de vida (foram programados para morrer em 4 anos). $O$ filme, embora se passe em Los Angeles, tem como inspiração a decadente Nova lorque do fim da década de 70 que era um retrato futuro da falência das grandes metrópoles: gangs, violência, incêndios, crimes. Nova lorque sempre foi considerada uma cidade "fantasia", construída entre 1890 e 1940 como experimento arquitetônico onde o céu era o limite das construções (skyscrapers), uma cultura de invenção permanente da metropolis, "fábrica de experiência feita pelo homem, onde o real e o natural cessaram de existir" (Koolhaas, 1994: 9-10) 
urbanos no plano do pesadelo, da ironia, revelando pela metáfora do futuro a questão do contemporâneo ${ }^{24}$. O cinema de Queirós discute, assim, o poder da tecnologia e das mercadorias no contexto de cidades pós-industriais (Begley, 2004: 188).

A cidade é uma só? cria, do mesmo modo que Blade Runner, um cityscape (Lussier \& Cowan, 2012: 170): estética urbana que apresenta suas contradições expressas pelas ideias de destruição e de fim de mundo. Apresenta este cenário posmetropolis (Brooker, 2005): a expansão das cidades, o excesso de alteridade, de exclusão, de violência e de controle. Modos de organizar um futuro possível a partir de uma crítica à racionalidade que dominou a construção de Brasília. A ênfase no "pós" é, justamente, a saída do moderno: espaços projetados como imaginário futurístico urbano.

As recepções críticas do filme enfatizam que Queirós procede a uma revisão da história, agora, contada pelos oprimidos que elaboram sua remoção para as cidades satélites e a exclusão de Brasília (Melo, 2013; Zanin, 2013). Queirós, por sua vez, deixa claro que seu filme não é uma "revanche", não necessita reafirmar politicamente sua voz e seu lugar. Filme "gângster" parece ser sua melhor definição. Filme de combate, destruição, ao não reificar Brasília faz emergir a cidade como ilusão. Ceilândia não é uma derrota do projeto arquitetônico, mas mundo possível porque distópico. Exibe em toda a sua plenitude o "efeito Blade Runner" em que destruição é potência reveladora, o que garante a insurgência do próprio filme enquanto mundo possível por ser um modo de compreensão de Ceilândia e de Brasília.

David Harvey (1989: 313-322) observa que, em Blade Runner, os conflitos não são postos no plano das classes sociais e nem a revolta é contra as corporações. Do mesmo modo, A cidade é uma só? estrutura seus conflitos no plano do espaço, de suas inclusões e exclusões. O filme, ao explorar as percepções espaciais, apresenta uma geografia distendida, permeada por autoritarismo, mais valia, sofrimento que se realizam nos espaços percorridos, nos trajetos, nas fronteiras. Os personagens se constroem em circulação, sendo os trajetos na cidade um laboratório prático-reflexivo sobre o espaço e seus significados sociais profundos. Existencializa os conflitos que, no plano do filme, são sempre espacializados. É deste modo que Queirós lembra de seus longos trajetos de ônibus, entre Ceilândia e UNB, saltando no ponto final depois de quase duas horas, em que percorria a paisagem de Brasília, seu plano, seu desenvolvimento urbano, apreendia uma Brasília da "perspectiva da janela". Seu deslocamento espacial o forçava a uma tomada de consciência "corporal" sobre Brasília e seu entorno.

$\mathrm{Na}$ universidade, "enquanto os seus colegas falavam de suas viagens para Nova lorque, Adirley falava da sua vida em Ceilândia. Assim, percebeu que para seus colegas sua cidade era tão distante quanto um outro planeta e foi aí, que o cineasta descobriu que a sua diferença poderia ser também o seu trunfo". (Ramos, 2014: 21). Vemos a alegoria interplanetária que Queirós explora em seus filmes revelando um Universo em que Brasília
23 | Queirós diz que "compra de caixa" para dar de presentes aos amigos.

24 Do mesmo modo, Blade Runner, através de projeções do futuro, lidava com questões contemporâneas da sociedade americana dos anos 70 e 80 (Scott, 1982). Blade Runner localiza o desvio no plano sexual, sua criminalização, no contexto do ativismo dos anos 70, nas cidades americanas, sobretudo, na Califórnia. Os protagonistas do ativismo sexual seriam os replicantes ou androides sendo apenas distinguíveis dos demais humanos por um aspecto sutil de sua moralidade, enquanto os blade runners exercem a força policial da criminalização (Yeates, 2017: 65). 
e Ceilândia se apresentam como planetas, galáxias, satélite ${ }^{25}$.

Queirós, desde que entra para UNB, investe em compreender a história de Ceilândia, faz 400 entrevistas com moradores, descortinando as potencialidades espaciais e cinematográficas de Ceilândia, narrada "pelos corpos" de seus moradores que acentuam tanto os processos de exclusão e a distância de Brasília quanto a inclusão de Ceilândia em um novo espaço de sua própria história. A percepção espacial ganha força conceitual a partir da leitura de Por uma outra globalização do geógrafo Milton Santos (2000). No contexto da percepção da segregação espacial, social e racial é que Queirós afirma que apenas um filme de terror daria conta do "real" de Brasília. Por isso, prefere realizar um filme 'gângster'." (Ramos, 2014:23).

O Ceicine organiza sessões deste cinema "gangster". Filmes projetados muitas vezes ao longo do ano, em "looping": Aguirre, Blade Runner, Serra da desordem, Mad Max e Bang Bang.

Dentre estes filmes destaca-se Serras da desordem, de Andrea Tonacci como inspiração permanente para Queirós (2017,) que admite ser um filme que assiste de forma recorrente. O filme segue o único sobrevivente indígena, Carapiru, de uma chacina que dizimou todos os seus parentes. Carapiru inicia uma longa jornada pelos sertões e matas até encontraruma família local que depoiso encaminha para a FUNAI. Neste percurso encontra o outro sobrevivente que é seu próprio filho, Txiramukum que habita no Posto Guajá. Seu tema se enquadra no "efeito Blade Runner", isto é, destruição, mundos distópicos em que o passado é o futuro e o futuro é incerto. Serras da desordem elabora a pós-memória de um mundo destruído, existindo apenas o que ele foi, uma imaginação que o filme materializa reencenando a história de Carapiru por ele mesmo. A cidade é uma só? e Serras da desordem tratam de um tempo que não existe mais, das fotografias, de pessoas mortas, de uma sociedade destruída, sobrevivências. Carapiru inventa outro mundo na sua deambulação. A encenação do coro das crianças que cantam "A cidade é uma só!" e a de Carapiru na mata antes do massacre sofrido nos remete a este outro tempo, espaço da memória vivificado pelas imagens como performance indiciática que permite criar mundos possíveis.

Queirós (2017) reconhece, na literatura, outra influência importante: Versos satânicos de Rushdie (1988). Os versos satânicos apresentam pontos de contato com o universo inspirador de Queirós ao apresentar a aventura de mulçumanos sobreviventes a um atentado a bomba que passam a desenvolver estranhas mutações físicas e sobrenaturais. Um deles, por exemplo, desenvolve chifres, casco e rabo. Outro, a partir de um anel de luz que emana de seu corpo, sonha em conhecer o profeta Maomé. Este seria um livro "gangster" que reinterpreta versos do corão, profanando a imagem de Maomé que no livro recebe o nome de Mahoun, pejorativo ao profeta.

Estes filmes, que Queirós assiste em "looping", têm temáticas em comum como o choque de sociedades e os processos entrópicos. Peter Szendy (2015:53-54;82,86), ao enquadrar Blade Runner como filme inaugural do gênero cinema apocalíptico,
25| Koolhaas (2016) em uma reflexão crítica e poética sobre Brasília e seu projeto modernista acentua a relação entre o futurismo arquitetônico e suas formas "óvnis" com a mística e magia ali instaurada no planalto central. 
acentua que embora o filme não trate propriamente do fim do mundo como tema ${ }^{26}$, nos dá a ver ideias sobre a finitude e processos históricos irreversíveis. Entropia, é uma noção importante para se pensar processos de irreversibilidade, do passado como destruição capaz de provocar a insurgência de mundos futuros. Mundos distópicos ou a própria concepção de entropia podem estar associadas ao desvio, ao caos, à desordem significando algo negativo como recusa de continuidades destes mundos enquanto possíveis. O que importa recuperar aqui, algo que ambos os filmes nos apontam, é a positividade das formas distópicas ou entrópicas ao produzirem uma reflexividade sobre a temporalidade, a existência, a identidade, a finitude, o contínuo e o descontínuo. É preciso evitar, porém, de um ponto de vista conceitual, a associação entre entropia e desordem. Uma importante ressalva a ser feita é que entropia não deve se confundir com a conceituação de anomia ou de patológico, como modos de se pensar as sociedades e culturas a partir das metáforas do organismo vivo. Entropia tem a vantagem de nos afastar deste modelo da biologia clássica e aceder a graus de complexidade instaurados pela termodinâmica que pensa a partir do modelo de "estruturas dissipativas" que estariam longe de um estado de "equilíbrio" (Prigogine, 1955).

A entropia aponta, seguindo a metáfora das máquinas, para uma "estrutura [que] se degrada... A noção de entropia dá um sentido único ao tempo. O tempo flui no sentido da perda da estrutura, da perda de informação, da perda de beleza". (Almeida, 1999: 177).

A potência da entropia é perceber que:

\footnotetext{
"há mais mundos possíveis desorganizados do que discretos, na maior parte do tempo o sistema é um mundo desorganizado. É essa a ideia básica da irreversibilidade: sistemas passam de estados improváveis para estados mais prováveis. Chamamos de entropia uma medida da probabilidade do estado em que o sistema se encontra: um sistema passa de estados de baixa entropia para estados de entropia alta" (Almeida , 1999: 183-184).
}

É neste sentido que entropia pode ser uma espécie de reservatório de promessas, o que garante a capacidade latente de emergência de novos mundos possíveis (Vergani, 2009: 261).

Brasília, no projeto modernista, encarnava a racionalidade, a ordem, em que o criador e a criatura se encontravam. Desenhada como máquina eterna sem atrito, afastava a entropia e a distopia de seu plano. Conjurava o tempo, a história, o desgaste. Entretanto, o fora do plano, no seu duplo sentido, produz alterações, incertezas, ao introduzir no "sistema Brasília" excesso de informação e gerar, assim, processos entrópicos ${ }^{27}$. Brasília, como posto por Niemeyer, tornou-se uma cidade como qualquer outra cidade do Brasil que se configura, arquitetonicamente, por planos superpostos de exclusões social, racial e espacial. Ceilândia cinematográfica

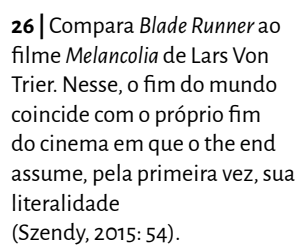

26 | Compara Blade Runner ao filme Melancolia de Lars Von Trier. Nesse, o fim do mundo coincide com o próprio fim do cinema em que o the end assume, pela primeira vez, sua literalidade (Szendy, 2015: 54).

27| Similar ao paradoxo babilônico das línguas, acúmulo de línguas, acúmulo de informações podem causar desordem (Arnheim, 2011: 15). 
transborda da tela como insurgência, reviramento de significados que não cessam de interrogar Brasília, agora, tornada centro dissipador contestatório que ecoa para todas as direções.

Marco Antonio Gonçalves é Professor Titular do Programa de Pós-Graduação em Sociologia e Antropologia da UFR] e do Departamento de Antropologia Cultural do IFCS-UFR]. É Mestre e Doutor em Antropologia Social pelo Programa Pós-Gradução de Antropologia Social do Museu Nacional-ufrj e realizou Pós-Doutorado na Universidade de St Andrews (1997), École des hautes études en sciences sociales (2005, 2008 e 2010), New York Universty (2015-2016) Bolsista de Produtividade em Pesquisa do CNPq - Nível 1D.

\section{REFERÊNCIAS BIBLIOGRÁFICAS}

ALMEIDA, Mauro W. B. de. 1999.

"Simetria e entropia: sobre a noção de estrutura de Lévi-Strauss". Revista de Antropologia, v. 42, n.1-2: 163-197.

ALMINO, João. 2007. "O mito de

Brasília e a literatura". Estudos

Avançados, v. 21, n. 59: 299-308.

ARDOIN, Paul. 2015. "'The courage to be a writer': Theorizing writerly courage in Burroughs's Blade Runner: a movie". The Papers of the Bibliographical Society of America, v. 109, n. 1: 63-81.

ARNHEIM, Rudolf. 2011. Entropy and art: an essay on disorder and order. Berkeley, University of California Press.

ATTLEE, James. 2007. "Towards anarchitecture: Cordon Matta-Clark and Le Corbusier". Tate Papers, Londres, n. 7..

BATISTA, Caio Bortolotti. 2018. Cinemae Alteridade: relações "eu"/outro" nas fronteiras entre o documentário e a ficção. Rio de Janeiro, Dissertação de mestrado ECO-UFR].
BEGLEY, Varum. 2004. "Blade Runner and the postmodern: a reconsideration". Literature/Film Quarterly, v. 32, n. 3: 186-192.

BORGES, Antonádia. 2009. “Explorando a noção de etnografia popular: comparações e transformações a partir dos casos das cidades-satélites brasileiras e das townships sul-africanas". Cuadernos de Antropologia Social, v. 29: 23-42.

BROOKER, Will. 2005. The Blade Runner experience: the legacy of a science fiction classic. New York, Columbia University Press.

BROOKER, Peter. 2005. Imagining the real: Blade Runner and discourses on the postmetropolis. In: Brooker, W. (org,) The Blade Runner experience: the legacy of a science fiction classic. New York, Columbia University Press.

BRUNO, Giuliana. 1987. "Ramble city: postmodernism and Blade Runner". October, v. 41: 61-74. 
BURROUGHS, William. 1979. Blade Runner: a movie. New York, Blue Wind Press.

CHEVRIER, Yves. 1983. "Blade Runner ou la sociologie d'antecipation". Esprit, n. 74: 138-143.

COSTA, Lúcio. 1973. "L’urbanisme de Brasilia". La Nouvelle Revue des Deux Mondes, Paris, Octobre: 129-133. 1991. Plano Piloto de Brasília.

Brasília, Secretaria de Cultura e Esportes.

COUTINHO, Eduardo. 1997. "O cinema documentário e a escuta sensível da alteridade". Projeto História São Paulo.

DESCOLA, Philippe. 2006. Par-delà nature et Culture. Paris, Gallimard.

DELEUZE, Gilles. 2005. A imagem-tempo. Cinema 2. São Paulo, Brasiliense.

FOUCAULT, Michel. 2013. O corpo utópico, as heterotopias. São Paulo, n-1 Edições.

GAUTHEROT, Marcel. 1960. The construction of Brasilia. New York, Park Books.

GONÇALVES, Marco Antonio. 2008. O real imaginado: etnografia, cinema e surrealismo em Jean Rouch. Rio de Janeiro, Topbooks. 2016. "Moscou: o encontro marcado entre Coutinho e Tchekhov e a construção de uma estética distópica". Novos estududos CEBRAP, v.35, n.3: 157-170.

HAESBAERT, Rogério \& BRUCE, Glauco. 2002. "A desterritorialização na obra de Dleuze e Guattari”. Geographia, v. 4, n.7: 1-15.

HARVEY, David. 1989. The condition of postmodernity. Oxford, Basil Blackwell.

HOLANDA, Frederico de. 1989. "Brasília: the daily invention of the city”. Ekistics, Atenas, v. 56, n. 334/335: 75-83.
HOLSTON, James. 1989. The modernist city: an anthropological critic of Brasilia. Chicago, University of Chicago Press. 1993. A cidade modernista: uma crítica de Brasília e sua utopia. São Paulo, Companhia. das Letras.

JAMESON, Frederic. 1991. Postmodernism, or, the cultural logic of late capitalism.

Duke, Duke University Press. 2006. Live Theory.

Nova York, Continuum.

KOOLHAAS, Rem. 1994. Delirious New York. A retroactive manifesto for Manhattan. New York, The Monacelli Press. 2016. "Brasília". Revista do centro, n. o.

LATOUR, Bruno. 1993. We have never been modern. Cambridge, Harvard University Press.

LEFEBVRE, Henri. 2001. O direito à cidade. São Paulo, Editora centauro.

LIMA, Tatiana Hora Alves de. 2016. "Imagens táticas contra utopia modernista: investigando as primeiras imagens de Brasília e A cidade é uma só?". Revista do Programa de Pósgraduação em Comunicação, v. 10, n. 2: 1-18.

LUSSIER, Mark \& COWAN, Kaitlin. 2012. "The Romantic Roots of "Blade Runner". The Wordsworth Circle, v. 43, n. 3: 165-172.

MACDOUGALL, David. 2006. The corporeal image. Film, ethnography, and the senses. Princenton, Princeton University Press.

\section{MANIFESTO OF SPACE HIJACKERS}

AND ANARCHITECTS. 1999. (https:// spacehijackers.org/html/manifesto.html)

MELO, Marco. 2013. A cidade é uma só? e outras ficções. (https://medium.com/fale-decinema/a-cidade- $\% \mathrm{C}_{3} \% \mathrm{~A}$-uma-s\% $\%$ C3\%B3-eoutras-fic\%C3\%A7\%C3\%B5es-5bb5e1a6883d) 
MCKINTY, Adrian. 2018. Do androids dream of electric sheep? A metaphysical detective story. (https://www.irishtimes.com/culture/books/ do-androids-dream-of-electric-sheep-ametaphysical-detective-story-1.3412034).

NOURSE, Alan E. 1974. The Blade

Runner. New York, Ballantine.

PFEIFER, Gottfried. 1964. "Quelques remarques à propos de Brasilia". Caravelle, n. 3: 389-400.

PRIGOCINE, Ilya. 1955. Thermodynamics ofirreversible processes. New York, John Wiley and Sons.

QUEIRÓS, Adirley. 2012. Reflexões sobre a linguagem documentária. (http://ceicinecoletivodecinema. blogspot.com/p/com-proposta-dediscutir-os-parametros.html) 2013. Ciclo Imageme

Alteridade. (https://www.youtube. com/watch?v=]pjpoMMnmws) 2014. $3^{\circ}$ Colóquio Cinema,

Estética e Política. Niterói, Universidade Federal Fluminense (https://www. youtube.com/watch?v=Wig(2b-u]XQ) 2015a. Diretor de "Branco Sai,

Preto Fica: fala do olhar da periferia. (https:// www.youtube.com/watch?v=fjbB]PrUsT4). 2015b. Encontros de

Cinema. (https://www.youtube. com/watch?v=Hdr8C2MR8vo.) 2017. Cinusp. https://www.

youtube.com/watch?v=m1]PhdUom54

RAMOS, Talita Silva Porto. 2014. Fora de campo: a identidade, a heterodoxia e o fazer cinematográfico de Adirley Queirós. Brasília, Monografia de Graduação, Curso de Ciências Sociais, Universidade de Brasília.
RIBEIRO, Gustavo Lins. 2006. El capital de la esperanza. La experiencia de los trabajadores en la construcción de Brasilia. Buenos Aires, Editorial Antropofagia.

RIZEK, Cibele Saliba. 1993.

"Paradoxos da Modernização". Novos

Estudos CEBRAP, n. 36: 38-42.

ROWLEY, Stephen. 2005. Blade Runner and the nightmare city. In: BROOKER, W. (org), The Blade Runner experience: the legacy of a science fiction classic. New York, Columbia University Press.

RUSHDIE, Salman. 1988. Os versos satânicos. São Paulo, Companhia das Letras.

SANTOS, Milton. 2000. Por uma outra globalização: do pensamento único à consciência universal. Rio de Janeiro, Record.

SCOTT, Riddley. 1982. Interview: Blade Runner. (https://www.youtube. com/watch?v=aw]J6hgoj8o)

SEVERO, Denise de Sousa. 2014. Planejamento urbano no Distrito Federal: o caso de Ceilândia. Brasília, Instituto de Ciências Humanas, Departamento de Ceografia, Universidade de Brasília.

SILVA, Mariana Duccini Junqueira da. 2015. "A cidade é uma só?: autoficcionalização, interrogação do arquivo e sentido de dissenso". Intertexto, n. 33: 76-89.

STENZEL, Emilia. 1993. "Arquitetura e utopia: O caso de Brasília". Iberoamerikanisches Archiv, v. 19 n. 1 e 2: 187-198.

SCHWARZ, Roberto. 2000. Ao vencedor as batatas. São Paulo, Duas cidades/Editora 34. 2012. Por que "ideias fora do lugar"?. In SCHWARZ, Roberto. Martinha versus Lucrécia: ensaios e entrevistas. São Paulo, Companhia das Letras. 
SZENDY, Peter. 2012. Apocalypse-cinema: 2012 and other ends of the world. New York, Fordham University Press.

TAVARES, Breitner. 2012. Na quebrada, a parceria é mais forte: jovens, vínculos afetivos e reconhecimento na periferia. São Paulo, Annablume; Brasília, Fundo de Apoio à Cultura do Distrito Federal.

VERGANI, Teresa. 2009. A criatividade como destino: transdiciplinaridade, cultura e educação. São Paulo, Editora Livraria da Física.

YANEVA, Albena. 2012. Mapping controversies in Architecture. Burlington, Ashgate Publishing Company.

YEATES, Robert. 2017. “Urban decay and sexual outlaws in the Blade Runner universe". Science Fiction Studies, v. 44, n. 1: 65-83.

ZANIN, Luiz. 2013. A cidade é uma só? (https://cultura.estadao.com.br/blogs/ luiz-zanin/a-cidade-e-uma-so/).

\section{FILMOGRAFIA}

ANDRADE, Joaquim Pedro de. 1967. Brasília, contradições de uma cidade nova. 24 min. Brasília.

CARVALHO, Vladimir. 1979. Brasilia segundo Feldman (com Eugene Feldman). 24 min. Brasília.
1991. Conterrâneos velho

de guerra. 175 min. Brasília.

HERZOG, Werner. 1977. Aguirre.

$95 \mathrm{~min}$. Alemanha.

QUEIROZ, Adirley. 2005. Rap, o canto da Ceilândia. 15 min. Brasília, Ceicine. 2009. Dias de greve.

24 min. Brasília, Ceicine. 2010. Fora de campo.

52 min. Brasília, Ceicine. 2011. A cidade é uma só? 72

min. Brasília, Ceicine, Cinco da norte. 2014. Branco sai, preto fica. 93 min. Brasília, Ceicine, 400 filmes. 2017. Era uma Vez Brasília.

100 min. Brasília, Ceicine, 400 filmes.

MILLER, George. 1979. Mad Max. 88 min. Austrália, Kennedy Miller Productions.

TONACCI, Andrea. 1971. Bang

Bang. 93 min. São Paulo. 2006. Serra da

Desordem. 135 min. São Paulo.

SANTOS, Nelson Pereira. 1966

Fala, Brasília. 18 min. Brasília.

SCOTT, Riddley. 1982. Blade Runner. 117 min. The Ladd Company.

VON TRIER, Lars. 2011. Melancholia. 136 min. Dinamarca, Nordisk Film.

Recebido em 15 de janeiro de 2019. Aceito em 10 de setembro de 2019. 